\title{
PENGGUNAAN MODEL COOPERATIVE LEARNING TIPE PROBING PROMPTING BERBANTU MEDIA FLASH CARD TERHADAP HASIL BELAJARIPS TERPADU
}

\author{
Rita Diartini $^{1)}$ Triani Ratnawuri ${ }^{2)}$ \\ Pendidikan Ekonomi FKIP Universitas Muhammadiyah Metro \\ Ritadiartini78@gmail.com ${ }^{1)}$ Triani_rw@yahoo.co.id ${ }^{2)}$
}

\begin{abstract}
The purpose of this research is to know the effect of learning probing prompting assisted flash card media to the learning outcomes of study of IPS integrated second semester class VII MTs Muhammadiyah Metro academic year 2016/2017. The population in this study is the students of class VII MTs Muhammadiyah Metro academic year 2016/2017 which amounted to 48 students. The sample used is class VIIB MTs Muhammadiyah Metro which amounts to 24 students as experiment class, while class VIIA become control class. This study aims to determine whether there is influence of the use of learning with Probing Prompting Helped Flash Card Media to the results of learning IPS integrated with the formula of simple linear regression. From the data analysis of the results of the study using simple linear regression formula with a significant level of $5 \%$ obtained $t_{\text {count }}=3.85$ while $t_{\text {table }}=1.72$ shows $t$ count $>$ $\mathrm{t}_{\text {table }}$, so the hypothesis accepted, that there is a significant influence from the use of probing prompting model assisted flash card media on the learning outcomes of study of IPS integrated second semester class VII MTs Muhammadiyah Metro academic year 2016/2017.
\end{abstract}

Keywords : Flash card, Learning outcomes, Probing prompting

\section{PENDAHULUAN}

Pendidikan merupakan suatu usaha yang dilakukan secara sadar dan sengaja untuk mengubah tingkah laku manusia baik secara individu maupun kelompok untuk mendewasakan manusia melalui upaya pembelajaran dan latihan. Pendidikan dapat juga diartikan sebagai pembelajaran yang diselenggarakan di sekolah sebagai lembaga pendidikan formal. Pendidikan nasional berdasarkan Undang-Undang Dasar Republik Indonesia Tahun 1945 mempunyai tujuan pendidikan sesuai dengan UU No.20 tahun 2003 tentang sistem pendidikan nasional menyatakan bahwa pendidikan berfungsi mengembangkan kemampuan dan membentuk watak serta peradaban bangsa yang bermartabat dalam rangka mencerdaskan kehidupan bangsa yang bertujuan untuk mengembangkan potensi siswa agar menjadi manusia yang beriman, bertaqwa, kepada tuhan Yang Maha Esa, berakhlak mulia, sehat, berilmu, cakap, kreatif, mandiri, dan menjadi warga negara yang demokratis dan bertanggung jawab. 
Keberhasilan dalam pembelajaran yaitu empat komponen utama yaitu tujuan, bahan, metode dan alat penilaian, dimana keempat komponen tersebut saling berhubungan dan saling mempengaruhi satu dengan yang lain. Dalam hal ini diperlukan langkah-langkah yang sistematis dalam menyampaikan pelajaran yang mampu membawa pada situasi yang aktif dimana siswa dapat mengembangkan segala kemampuan belajar dan berpikir kritis.

Langkah-langkah yang sistematis dalam proses pembelajaran merupakan bagian yang penting dari strategi mengajar, dimana strategi tersebut tidak lepas dari pemilihan metode pembelajaran sehingga pelaksanaan belajar dapat berjalan dengan lancar. Dalam menentukan metode kita juga harus menyesuaikan materi yang akan diajarkan yang sesuai atau cocok pada metode pembelajaran yang akan dipilih. Ada bermacam-macammetode yang dapat dipilih dan digunakan oleh guru dalam proses pembelajaran agar siswa dapat mencapai hasil belajar yang optimal. Karena setiap metode yang dipilih dan digunakan akan membawa pengaruh langsung ataupun tidak langsung dalam mencapai hasil belajar yang diharapkan. Namun dalam kenyataannya tidak semua dapat mencapai hasil belajar yang diharapkan. Hal ini disebabkan oleh beberapa factor baik faktor yang ada dalam diri siswa maupun faktor yang ada di luarsiswa.

Proses pembelajaran IPS terpadu selama ini cenderung ditunjukan siswa pada keterampilan siswa menyelesaikan soal-soal saja tetapi dalam menyelesaikan sebuah masalah atau memecahkan sebuah permasalahan cenderung kurang. Untuk mengatasi kesulitan belajar siswa dalamrangkamencapaitujuanintruksionalm aka model probing prompting berbantu media flash card sangat cocok diterapkan dalam bidang studi IPS terpadu.

Berdasarkan latar belakang tersebut di atas ditemukan masalah yaitu masih ada siswa yang belum tuntas hasil belajar IPS Terpadu siswa kelas VII semester genap MTs Muhammadiyah Metro Tahun Pelajaran 2016/2017. Berdasarkan rumusan masalah, yang menjadi tujuan dalam penelitian ini adalah: "Untuk mengetahui pengaruh penggunaan model Cooperative Learning tipe Probing Prompting berbantu media Flash Card terhadap hasil belajar IPS terpadu siswa kelas VII semester genap MTs Muhammadiyah Metro tahun pelajaran 2016/2017'.

\section{KAJIAN PUSTAKA}

Hasil belajar siswa adalah suatu pencapaian yang dilakukan oleh siswa 
dalam proses pembelajaran, karena belajar pada dasarnya adalah bagaimana perilaku seseorang berubah sebagai akibat dari pengalaman, perubahan perilaku tersebut meliputi ranah kognitif, afektif, dan psikomotorik.Menurut

Kunandar (2010:276) hasil belajar adalah "suatu akibat dari proses belajar dengan menggunakan alat pengukuran, yaitu berupa tes yang disusun secara terencana, baik tes tertulis, tes lisan maupun tes perbuatan".Dari pendapat tersebut dapat diambil pengertian bahwa hasil belajar yaitu suatu proses yang dilakukan seseorang dalam rangka untuk meraih hasil yang diinginkan dengan proses dengan menggunakan alat ukur berupa tes secara tertulis maupun lisan.

Model Cooperative Learning adalah suatu strategi pembelajaran yang menekankan pada prilaku dalam sikap atau perilaku dalam bekerja atau membantu diantara sesama dalam struktur kerjasama yang teratur dalam kelompok, yang terdiri dari dua orang atau lebih. Pembelajaran cooperative learning merupakan strategi belajar dengan sejumlah siswa sebagai anggota kelompok kecil yang tingkat kemampuannya berbeda dalam pelajaran. Adapun tipetipecooperative learningmenurut Suyatno (2009:52)sebagai berikut :

a) Number Heads Together (NHT) b) Jigsaw

c) Think Pair Share (TPS)

d) Teams-Games-Tournament (TGT)

e) Group Investigation (GI)

f) Contextual Teacing And Learning (CTL)

g) Team Acelerated Instruction (TAI)

h) Problem Based Intruction (PBI)

i) Realistic Mathematics Education (RME)

j) Problem Posing

k) Open Ended (Problem Terbuka)

1) Probing-Prompting

m) Cyle Learning

n) Reciprocal Teacing

o) Think-Pair-Share

p) Number Heads Together

q) Group Investigation

r) Two Stay Two Stray

s) Make A Match

t) Listening Team

\section{Tipe Probing Prompting}

Menurut Fahris dan Puput (dalam Zaeni 2014:90) menyatakan bahwa, Probing adalah menggali atau melacak, dan Prompting adalah mengarahkan atau menuntun. Secara umum pembelajaran dengan menggunakan probing prompting adalah pembelajaran dengan cara guru menyajikan serangkaian pertanyaan yang sifatnya menuntun dan menggali sehingga 
terjadi proses berpikir yang mengaitkan pengetahuan baru yang sedang dipelajari.

Pembelajaran dengan probing prompting memiliki beberapa kelebihan dalam penerapanya di pembelajaran menurut(Nurjanah, 2013:22-23) sebagai berikut:

1) Mendorong siswa aktif berpikir

2) Memberi kesempatan kepada siswa untuk menanyakan hal - hal yang kurang jelas sehingga guru dapat menjelaskan kembali.

3) Perbedaan pendapat antara siswa dapat dikompromikan atau diarahkan pada suatu diskusi.

4) Pertanyaan dapat menarik dan memusatkan perhatian siswa, sekalipun ketika itu siswa sedang ribut, yang mengantuk, kembali tegar dan hilang kantuknya.

5) Sebagai cara meninjau kembali (review) bahan pelajaran yang lampau.

6) Mengembangkan keberanian dan keterampilan siswa dalam menjawab dan mengemukakan pendapat.

\section{Flash Card}

Menurut Yetti (2015) flash card merupakan suatu media yang menggunakan gambar-gambar yang digantung pada suatu tiang gantungan kecil dan cara menunjukan dengan membalik satu per satu.Flash card sangat cocok untuk pembelajaran dengan menggunakan tipe probing prompting, dengan menggunakan metode probing prompting berbantu media flash card siswa dapat lebih memahami dengan baik dan cepat menangkap materi karena siswa belajar untuk memecahkan masalah. Sehingga hasil belajar siswa mengalami perubahan prilaku yang relevan.

\section{METODE PENELITIAN}

Penelitian ini menggunakan model eksperimen Quasi experimental design. Karena desain ini mempunyai kelompok kontrol, tetapi tidak dapat sepenuhnya mengontrol variabel-variabel dari luar yang mempengaruhi jalannya eksperimen. Menurut Sugiyono (2011:122) ciri utama dari Quasi eksperimental design adalah bahwa sampelnya yang digunakan untuk eksperimen maupun sebagai kelompok kontrol diambil secara random dari populasi tertentu.

Populasi dalam penelitian ini yaitu seluruh siswa kelas VII MTs Muhammadiyah Metro tahun pelajaran 2016/2017, yaitu yang berjumlah 48 siswa yang terdiri dari 2 kelas yaitu : Kelas VII $\mathrm{A}=24$ siswa dan Kelas VII B = 24 siswa. Kelas eksperimen yang digunakan adalah kelas VII B dan kelas VII A menjadi kelas kontrol. 


\section{PEMBAHASAN HASIL PENELITIAN}

Sebelum alat ukur pretest dan postest diujikan pada sampel penelitian, terlebih dahulu diuji coba alat ukur tersebut pada siswa diluar kelas sampel. Hasil ujicoba validitas dan reliabilitasdiperoleh bahwa soal pretestdan postest yang valid dan reliabel berjumlah 20 soal. Kemudian dalam penelitian ini dilakukan langkahlangkah untuk mendapatkan data penelitian yang akurat sebagai pengujian hipotesis, berikut ini:
1. Tahap persiapan penelitian

2. Tahap Awal Pelaksanaan Perlakuan (Treatment) Penelitian

3. Tahap Pelaksanaan Perlakuan (Treatment) Penelitian yaitu penggunaan model cooperative learning tipe probing prompting berbantu media flash card

Setelah dilakukan treatment diperoleh data hasil belajar. Berikut ini tabel yang menampilkan hasil belajar pretest dan postest.

Tabel 1. Hasil belajar IPS terpadu pada siswa kelas VIIB Semester Genap di MTs Muhammadiyah Metro Tahun Pelajaran 2016/2017

\begin{tabular}{|l|c|c|c|c|c|c|}
\hline \multirow{2}{*}{ No } & \multirow{2}{*}{$\begin{array}{c}\text { Interval } \\
\text { Nilai }\end{array}$} & Kategori & \multicolumn{2}{|c|}{ Evaluasi PreTest } & \multicolumn{2}{c|}{ Evaluasi PostTest } \\
\cline { 3 - 7 } & & $\begin{array}{c}\text { Jumlah } \\
\text { siswa }\end{array}$ & Presentase & $\begin{array}{c}\text { Jumlah } \\
\text { siswa }\end{array}$ & Presentase \\
\hline 1 & $\geq 78$ & Tuntas & 14 & 58,4 & 18 & 75 \\
\hline 2 & $<78$ & Tidak tuntas & 10 & 41,6 & 6 & 25 \\
\hline \multicolumn{3}{|c|}{ Jumlah } & $\mathbf{2 4}$ & $\mathbf{1 0 0}$ & $\mathbf{2 4}$ & $\mathbf{1 0 0}$ \\
\hline
\end{tabular}

Sumber: Hasil belajar IPS terpadu siswa kelas VIIB Semester Genap di MTs Muhammadiyah Metro dari hasil penelitian

Berdasarkan tabel diatas dapat diketahui bahwa pada tahap evaluasi uji pretest, siswa yang mencapai tuntas belajar hanya 58,4\% (14 siswa), sedangkan siswa yang belum mencapai tuntas belajar adalah 41,6\% (10 siswa). Dengan demikian dapat ditemukan bahwa jumlah siswa yang belum tuntas belajar atau belum mencapai standar ketuntasan yang telah ditetapkan masih banyak yaitu 41,6\% atau 10 siswa dari total keseluruhan siswa sebanyak 24 siswa. Dengan demikian tabel diatas juga dapat menunjukkan bahwa pada tahap evaluasi uji posttest, setelah siswa mendapatkan treatment atau perlakuan menggunakanpembelajaran model probing prompting berbantu media flash card yang mencapai tuntas belajar berjumlah $75 \%$ (18 siswa), sedangkan siswa yang belum mencapai tuntas belajar berjumlah $25 \%$ (6 siswa), dari total keseluruhan siswa sebanyak 24 siswa. 
Berdasarkan penelitian ini setelah siswa mendapatkan treatment atau perlakuan menggunakan pembelajaran model probing prompting berbantu media flash card terhadap hasil belajar ips terpadu mengalami peningkatan dapat dilihat berdasrkan tabel diatas, yaitu siswa yang mencapai kriteria ketuntasan evaluasi pretest adalah 58,4\% (14 siswa)dari total keseluruhan siswa sebanyak 24 siswa, sedangkan siswa yang mencapai kriteria ketuntasan evaluasi posttest adalah $75 \%$ (18 siswa), dari total keseluruhan siswa sebanyak 24 siswa. karena penggunaan model probing prompting berbantu media flash card ini menekankan siswa lebih aktif lagi dalam proses pembelajaran. Berdasarkan analisis data hasil belajar ips terapdu diperoleh hasil penelitian yang sesuai dengan rumusan masalah dan tujuan penelitian yaitu sebagai berikut:

Berdasarkan perhitungan dengan rumus regresi linier sederhana dengan menggunakan $t_{\text {hitung }}\left(t_{\mathrm{o}}\right)$ dalam analisis data dapat diketahui bahwa analisis perhitungan nilai tersebut $t_{\text {hitung }}>t_{\text {tabel, }}$ pada taraf signifikan $5 \%$ yaitu 3,85>1,72 yaitu $\mathrm{t}_{\text {hitung }}$ lebih besar 2,13 dari $t_{\text {tabel. Dengan }}$ membandingkan $t_{\text {hitung }}$ dengan $t_{\text {tabel }}$ jika $t_{\text {hitung }}>t_{\text {tabel }}$ berarti hipotesisnya diterima .

\section{KESIMPULAN}

Berdasarkan hasil analisis, disimpulkan bahwa ada pengaruh yang signifikan penggunaan pembelajaran model Probing prompting berbantu media flash card terhadap hasil belajar IPS terpadu siswa kelas VIIbMTs Muhammadiyah Metro tahun pelajaran 2016/2017. Hal ini dibuktikan dengan penghitungan analisis data dapat diketahui bahwa nilai $t_{\text {hitung }}>t_{\text {tabel}}$, dengan taraf signifikan $5 \%$ yaitu $3,85>1,72$.

Sebagai saran bagi guru untuk menjadi lebih aktif dan lebih berkembang dalam proses pembelajaran dengan penggunaan model pembelajaran yang bervariasi sehingga mampu manumbuhkan rasa ingin tahu siswa untuk menggali informasi dengan lebih banyak sehingga diharapkan hasil belajar IPS terpadu mereka menjadi lebih baik. Sedangkan bagi siswa disarankan untuk dapat lebih aktif dalam mengikuti proses pembelajaran dikelas dengan model pembelajaran yang telah disampaikan guru.

\section{DAFTAR PUSTAKA}

Kunandar. 2010. Penelitian Tindakan Kelas. Jakarta: PT. Rajawali.

Sugiyono. 2011. Metodologi Penelitian kuantitatif Kualitatif Dan $R \& D$.

Suyatno. 2009. Menjelajah pembelajaran inovatif. Sidoarjo: Masmedia Buana Pustaka 
e-ISSN 2442-9449 Vol.5. NNo.1 (2017) 57-63

p-ISSN 2337-4721

Yetti, Misna. 2015. flipchart an

flashcard.(http://misnayetti95.blogspot.co

.id /2015/06/flipchart- flashcard.html).

Zaeni. 2014.pengertian metode probing

prompting. (http://faqihzaeni.

blogspot.co.id /2014/12/pengertian-

metode-probing-prompting.html) 